\title{
(IN)EFETIVIDADE DOS DIREITOS HUMANOS FRENTE A CRISE DO MODELO ESTATAL ${ }^{1}$
}

\author{
Raquel Buzatti Souto ${ }^{2}$
}

\begin{abstract}
RESUMO
A estrutura estatal vem passando por uma desconstrução dos paradigmas que orientaram a organização de sua estrutura institucional. Há uma fragilização dos instrumentos sociais, políticos e jurídicos garantidores de uma ordem social ocasionados por transformações no poder do Estado, nos seus diversos setores, destacando no que concerne à promoção e proteção dos direitos humanos. Assim, a sociedade se torna díspar e as instituições protetivas sociais e jurídicas não estão alcançando a funcionalidade e a operatividade necessária para obter um efetivo controle social acarretando o que se chama de uma (in) efetividade dos sistemas normativos e obrigando à busca da adequada proteção a esses direitos.
\end{abstract}

PALAVRAS-CHAVE: efetividade - direitos humanos - crise - Estado.

\begin{abstract}
The state structure comes passing for a descontrucion of the paradigms that had guided the organization of its institucional structure. It has an embrittlement of the social instruments, politicians and legal guarantors of a social order caused by transformations in the power of the State, its diverse sectors, detaching with respect to the promotion and protection of the human rights. Thus, the society if becomes to díspar and the social and legal protetivas institutions are not reaching the functionality and the operatividade necessary to get an effective social control causing what it is called one (in) effectiveness of the normative systems and compelling to the search of the adjusted protection to these rights.
\end{abstract}

KEY-WORDS: effectiveness - right human beings - crisis - State.

\section{INTRODUÇÃO}

A proposta central do artigo é enfocar o problema da (in) efetividade dos direitos humanos no atual contexto jurídico-político-social mundial diante do modelo estatal. A problemática em questão é tentar buscar solução para resolver os problemas decorrentes da crise do Estado que abalam de uma forma ou de outra a estrutura da (in) efetividade dos direitos fundamentais diante de uma escassez legislativa.

\footnotetext{
${ }^{1}$ Artigo apresentado na disciplina Direitos Humanos, Acesso à Justiça e Desenvolvimento, no programa de Pós-Graduação Stricto Sensu em Desenvolvimento pela Universidade Regional do Noroeste do Estado do Rio Grande do Sul (UNIJUí), ministrada pelo Prof. Msc. Doglas Cesar Lucas.

${ }^{2}$ Mestranda do Programa de Pós-Graduação Stricto Sensu em Desenvolvimento pela UNIJUÍ, na linha de pesquisa Direito, Cidadania e Desenvolvimento. Especialista em Direito Constitucional Aplicado: uma abordagem material e processual pela UNIFRA. Professora do Curso de Direito da UNICRUZ. Advogada. Endereço eletrônico: raquelsouto@terra.com.br
}

$$
\text { ISSN - 1981-3694 }
$$

(C) 2007. Departamento de Direito da UFSM. Todos os direitos reservados. 
A preocupação em buscar soluções para a efetividade dos direitos humanos vai ao encontro da definição desses direitos, como direitos fundamentais e inerentes ao ser humano enquanto indivíduo ${ }^{3}$. Inquietações, essas, relacionadas à dignidade da vida quotidiana dos indivíduos, dos grupos sociais, da humanidade e de todos os seres que habitam o planeta.

Observa-se, nos últimos tempos uma transformação no campo político, social e jurídico no que concerne aos direitos humanos. Eles estão positivados, mas não são operacionalizados. Assim, tenta-se com este trabalho alcançar a idéia da busca por uma efetiva (e eficaz) reformulação deste contexto, a fim de que se possa vislumbrar a prática desses direitos.

Diante da conjuntura crítica da desconstrução do modelo estatal, centrada, principalmente, no novo perfil mercadológico mundial-globalizado ${ }^{4}$, recorre-se, hoje, à busca de uma nova ordem social consagrada pela valorização dos direitos humanos e sua real operatividade e efetividade. Para que isto se concretize, busca-se uma reformulação nas políticas públicas, enfatizando-se o modelo educacional ${ }^{5}$.

A fim de organizar este trabalho, elencou-se dois capítulos, organizados a partir de uma pesquisa bibliográfica com a utilização de textos jurídicos, possibilitando levantar aspectos relevantes acerca do tema proposto.

\footnotetext{
3 No dizer de Hannah Arendt, os direitos humanos não são um dado, mas um construído, uma invenção humana, em constante processo de construção e reconstrução. (LAFER, Celso. $A$ reconstrução dos direitos humanos: um diálogo com o pensamento de Hannah Arendt. São Paulo: Cia. das Letras, 1988, p. 134).

O fenômeno da globalização está sendo impulsionado pela expansão do mercado internacional, o qual não supõe, necessariamente, a emergência simultânea de uma sociedade mundial integrada. De fato, esse processo parece estar contribuindo mais à despolitização da maioria da população mundial e sua manipulação por parte de algumas elites técnico-burocáticoempresariais, que à construção consciente de uma sociedade global. (SHERRER-WARREN, Ilse. Cidadania e Multiculturalismo: a teoria social no Brasil contemporâneo. Florianópolis: Ed. UFSC, 2000, p. 54).

5 Educação desde e para os Direitos Humanos forma o sujeito de direito tanto coletiva como individualmente, articulando as dimensões ética e político-social com práticas concretas. Além disso, favorece o processo de "empowerment" (empoderamento), fazendo com que os homens reconheçam o poder que lhes é intrínseco, se reconheçam enquanto atores sociais e se organizem coletivamente em busca do mínimo necessário à sobrevivência. (WARAT, Luis Alberto. Curso seqüencial: formação de educadores desde e para os direitos humanos. Brasília: MEC, 2003, p. 12. Disponível em: 〈http://www.mec.gov.br/univxxi/pdf/curso1.pdf> Acesso em: 6 set. 2006.)
} 
No primeiro capítulo, abordou-se o referencial histórico da crise do Estado, o pressuposto rompimento de seu modelo, as crises que perpassaram e perpassam sua estrutura e as problemáticas mundiais surgidas até então.

Em um segundo momento, passou-se ao estudo da real inquietação da (in) efetividade dos direitos humanos no contexto social-político-jurídico, abordando-se, rapidamente, a influência do processo da globalização.

E, por fim, tomando-se como orientação as colocações ao longo do texto, sem, no entanto, encerrar qualquer discussão, apresentam-se as considerações finais, as quais possuem o objetivo de despertar a sociedade, o Estado, bem como alcançar os estudantes de direito para uma temática tão preocupante e atual quanto esta.

\section{A CRISE DO ESTADO E SUAS CONSEQUÊNCIAS}

Viver em sociedade fez com que o homem buscasse formas de adaptação social, mecanismos e instrumentos de funcionamento da sociedade ${ }^{6}$. Assim, nasce a figura do Estado, significando uma situação permanente de convivência entre os diversos grupos sociais, caracterizando uma sociedade politicamente organizada e voltada a consecução de um fim comum ${ }^{7}$.

Esse novo modelo institucional, regulado e sistematizado em prol da sociedade e da busca de um bem comum, para se adaptar a cada momento histórico ${ }^{8}$ moldado por cada época, passou por uma evolução histórica em suas características e em seu modelo como organizador da ordem social.

Assim, a evolução do Estado se deu em prol do desenvolvimento das características dominantes da organização estatal através das diversas ordens e

6 Os agrupamentos humanos caracterizam-se como sociedades quando têm um fim próprio e, para sua consecução, promovem manifestações de conjunto ordenadas e se submetem a um poder, e no tocante à sociedade humana, globalmente considerada, verificamos que o fim a atingir é o bem comum. (DALLARI, Dalmo de Abreu. Elementos de Teoria Geral do Estado. 25. ed. São Paulo: Saraiva, 2005, p. 46).

Segundo o Papa João XXIII, bem comum significa o conjunto de todas as condições de vida social que consintam e favoreçam o desenvolvimento integral da personalidade humana.

$8 \quad$ Desde seu aparecimento como organização do meio nacional, desde as mais primitivas formas de associação política, o Estado, elemento dinâmico por excelência, vem evoluindo sempre, e refletindo, nessa evolução, a trajetória ascensional da civilização humana. O seu desenvolvimento não segue, naturalmente, uma progressão retilínea: avanços arrojados, retrocessos profundos, longas estagnações e até mesmo eclipses duradouros assinalam a sua marcha no tempo e no espaço. (MALUF, Sahid. Teoria Geral do Estado. 26.ed. São Paulo: Saraiva, 2006, p. 91). 
estágios da civilização. Foram diversas teorias que tentaram explicar a transformação ocorrida do modelo estatal, destacando a que insere ao desenvolvimento em: Estado Antigo, Estado Grego, Estado Romano, Estado Medieval e Estado Moderno 9 .

Um dos pontos marcantes da evolução histórica do Estado e o seu modelo estrutural, foi a transição do modelo do Estado medieval para um novo modelo de Estado, uma nova realidade ${ }^{10}$, ou seja, uma nova afirmação do poder político - o Estado Moderno ${ }^{11}$. Nesse viés acrescenta-se Streck (2006, p. 43) sobre a essa nova ordem paradigmática:

\begin{abstract}
O rompimento paradigmático da velha ordem medieval para a nova ordem se dá principalmente através da passagem das relações de poder (autoridade, administração da justiça, etc.) - até então em mãos privadas do senhor feudal -, para a esfera pública (o Estado centralizado). Com isso, estabelecia-se a dicotomia público-privado ou sociedade civil/sociedade política.
\end{abstract}

O aparecimento desse novo modelo foi um processo lento e progressivo na história. O Estado Moderno surge com uma roupagem diferente, com características próprias, dentre elas, a concentração e a centralização do poder, uma organização burocrática de poder a serviço da população e de todos. Tal modelo é vislumbrado

9 Como outra forma de apresentar a evolução do Estado nos seus diversos momentos históricos, MALUF citando LIMA prescreve: "Queiroz Lima adotou para a sua exposição doutrinária a seguinte fórmula: $1^{\circ}$ ) o Estado primitivo foi teocrático, explicado pelas teorias do direito divino sobrenatural; $2^{\circ}$ ) vem, a seguir, a noção metafísica do Estado, deslocando para a vontade do povo a origem do poder soberano; $3^{\circ}$ ) segue-se a noção positiva do Estado, segundo o qual a soberania decorre das próprias circunstâncias objetivas, do império da lei ou da concepção realista do Estado como força a serviço do direito". (MALUF, Sahid. Teoria Geral do Estado. 26.ed. São Paulo: Saraiva, 2006, p. 91).

10 O nome Estado é um novo nome para uma realidade nova: a realidade do Estado precisamente moderno, a ser considerado como uma forma de ordenamento tão diversos dos ordenamentos precedentes que não podia mais ser chamado com os antigos nomes. (BOBBIO, Norberto. Estado, Governo e Sociedade: para uma teoria geral da política. Traduzido por Marco Aurélio Nogueira. Rio de Janeiro: Paz e Terra, 1987, p. 65).

11 A origem do Estado moderno se encontra no árduo processo de constituição de uma única autoridade com poder sobre todas as pessoas e atividades de um mesmo território. A necessidade de acabar com as guerras civis e religiosas, que arruinavam e sangravam as sociedades européias, foi a justificativa (teórica e histórica) para a monopolização do poder público na mão do soberano (neutralizando, em conseqüência, qualquer poder baseado na sociedade civil). (SHERRERWARREN, Ilse e outros. Cidadania e Multiculturalismo: a teoria do social no Brasil contemporâneo. Florianópolis: UFSC, 2000, p. 65). 
sob duas vertentes, quais sejam, a aparição do Estado Moderno na sua forma absolutista e a aparição do Estado Moderno em sua forma liberal.

Cabe ressaltar, fazendo parte do objeto de estudo do proposto tema, o Estado Moderno em sua segunda versão o Estado-Liberal. Também denominado de Estado Constitucional, foi uma forma estatal que rompeu paradigmaticamente com a velha ordem estatal, começando a haver, neste momento, uma intervenção minimalista do Estado na sociedade como forma de desenvolvimento social ${ }^{12}$.

O modelo liberal do Estado Moderno começa a apresentar fragilização em sua estrutura no que concerne a promoção do desenvolvimento econômico e social. A sociedade principia a se transformar, exigindo, assim, do Estado uma política mais intervencionista com atitudes e prestações positivas ${ }^{13}$.

Em meados do século XIX, observa-se uma mudança dessa forma estatal liberal, quando o Estado passa a assumir tarefas positivas, prestações públicas a serem asseguradas aos cidadãos como direitos de cidadania. Iniciando-se, assim, um novo processo de transformação do Estado, até então minimalista, para um Estado Social (Welfare State - significa Estado do Bem Estar Social), uma nova justiça social com espírito de ajuda, cooperação e serviços mútuos, inaugurando uma nova fase do Estado na história ${ }^{14}$.

Hoje, o que se observa é que esse modelo estatal novo está em crise, decorrente das inúmeras transformações em seu contexto. Uma crise que podemos denominá-la conceitual, estrutural, funcional, enfim, uma crise do seu modelo

12 BEDIN citando PERRY: "O indivíduo dos tempos modernos assistiu ao crescimento de uma economia de mercado capitalista, cujo foco principal era o indivíduo auto-suficiente, diligente, de espírito prático e motivado por interesses pessoais". (BEDIN, Gilmar Antonio. A sociedade internacional e o século XXI: em busca da construção de uma ordem mundial justa e solidária. Ijuí: Ed. UNIJUÍ, 2001, p. 108).

13 O Estado liberal, com um mínimo de interferência na vida social, trouxe, de início, alguns inegáveis benefícios: houve um progresso econômico acentuado, criando-se condições para a revolução industrial; o indivíduo foi valorizado, despertando-se a consciência para a importância da liberdade humana; desenvolveram-se as técnicas de poder, surgindo e impondo-se a idéia do poder legal em lugar do poder pessoal. Mas, em sentido contrário, o Estado liberal criou as condições para a sua própria superação. (DALLARI, op.cit., p. 280).

14 Importante fazer referência, diante do nascimento do Estado Moderno, que essa forma estatal passa a ser o principal ator, senão o único, das relações internacionais, afirmando-se, definitivamente, como centro da articulação política da sociedade internacional que está surgindo. Essa nova sociedade surge a partir da chamada Paz de Vestfália, que é o momento culminante de afirmação e de consolidação do Estado Moderno. (BEDIN, op.cit., p.159). 
paradigmático $^{15}$. Cita-se, nesse sentido, a preocupação de Streck (2006, p.249) com a banalização das teses e expressões no âmbito do Direito:

[...] expressões como "caso concreto", hermenêutica", "interpretação", "discurso", "argumentação" e "concretização" vêm sofrendo de forte anemia significativa. Em face desse estado d'arte e na medida em que a problemática acerca da interpretação é uma questão que envolve concorrência de ou entre paradigmas de direito, de précompreensões acerca de como se deve interpretar e aplicar direito [...]

Nesse viés, a crise paradigmática estatal, afeta, dentre outros setores do Estado, o seu poder soberano. A soberania está perdendo o valor para o qual foi pensada, há uma desconstrução e reconstrução do fenômeno soberania. A soberania é constituída e constitutiva da formação do Estado-Nação e esse está em ruínas.

A humanidade vive um momento social diferenciado. As realidades são outras, vive-se a era do novo tempo, das sociedades pluralistas e complexas ${ }^{16}$ ao fenômeno da globalização. Fenômeno este de mundialização dos povos e de rompimentos das fronteiras tradicionais.

Diante desse processo da globalização ${ }^{17}$, vislumbra-se a insurgência de uma despolitização da maioria da população mundial e sua manipulação por parte de algumas elites técnico-burocrático-empresariais. Um novo mundo, caracterizado pelo global ou mundial, apresenta-se sob a faceta de uma comunidade globalfragmentada.

15 Há uma crise conceitual, que questiona o poder como soberania; a crise estrutural; a própria crise constitucional, onde aparecem as interfaces entre política, Direito e economia; a crise estrutural e a crise política e da representação. (ENGELMANN, Wilson. A Crise Constitucional: a linguagem e os direitos humanos como condição de possibilidade para preservar o papel da Constituição no mundo globalizado. Morais, José Luis Bolzan de. (org). O Estado e suas crises. Porto Alegre: Livraria do Advogado, 2005, p. 226).

16 A questão da complexidade é complexa. Mas a complexidade tem dificuldades em se manifestar. Ela tem dificuldade de emergir, em princípio, porque não foi o centro de grandes debates e de grandes reflexões. Assim, a primeria vista a complexidade aparece como irracionalidade, incerteza, confusão, desordem. A idéia da complexidade é uma aventura. (MORIN, Edgar. A inteligência da complexidade. 2.ed. Editora fundação Peirópolis).

17 A "globalização" está na ordem do dia; uma palavra da moda que se transforma rapidamente em um lema, uma encantação mágica, uma senha capaz de abrir as portas de todos os mistérios presentes e futuros. Para alguns "globalização" é o que devemos fazer se quisermos ser felizes, para outros, é a causa da nossa infelicidade. (BAUMAN, Zygmunt. Globalização: as consequiências humana. Tradução de Marcus Penchel. Rio de Janeiro: Jorge Zahar Editor, 1999, p. $7)$. 
Pode-se, aqui, mencionar, que a esse novo processo mundial está desmoronando a construção do Estado e com ele a ruptura do Estado-Nação, ocasionando uma crise no modelo estatal, vindo a se propagar diante da velocidade e da quantidade de informação em nível global. Nesse sentido, Bauman (1999, p. 63) insere sobre a incidência dessa nova ótica mundial:

O significado mais profundo transmitido pela idéia da globalização é o do caráter indeterminado, indisciplinado e de autopropulsão dos assuntos mundiais; a ausência de um centro, de um painel de controle, de uma comissão diretora, de um gabinete administrativo. A globalização é a "nova desordem mundial" de Jowitt com outro nome.

Essa integração mundial faz com que a intervenção estatal diminua ou desapareça. O processo da globalização ${ }^{18}$ acarreta em termos mundiais um novo paradigma tecnológico, enfraquecendo o Estado-Nação ${ }^{19}$, abolindo as fronteiras nacionais, gerando inúmeros problemas e confrontações.

As mudanças estruturais e políticas ocasionadas por esse fenômeno global vêm provocando transformações no Estado ${ }^{20}$, ocasionando uma redefinição dos fins buscados por ele. Essa estrutura clássica não está encontrando aporte para conseguir cumprir o seu papel, desempenhar as suas funções e alcançar a soberania plena.

O rumo dessa fragilização e desfragmentação do modelo clássico estatal observada nos dias atuais, diante desse novo contexto social-jurídico-político

18 Por óbvio, que o parco da globalização não foi montado todo ele de uma só vez, em um só tempo. O processo acirrou-se a partir do contexto do segundo pós-guerra, tendo o seu germe em períodos anteriores da história. A partir de então, nesse momento de reconstrução do mundo, percebe-se uma forte tendência à internacionalização do capital, desenhada pela busca de espaços mais amplos e desregulamentados. (ESPÍNDOLA, Angela Araújo da Silveira. A crise conceitual e a (re)construção interrompida da soberania: o fim do Estado-Nação?. MORAIS, José Luis Bolzan de. (org). O Estado e suas crises. Porto Alegre: Livraria do Advogado, 2005, p.30). 19

A capacidade instrumental do

Estado-Nação está comprometida de forma decisiva pela globalização das principais atividades econômicas, pela globalização da mídia e da comunicação eletrônica e pela globalização do crime. (CASTELLS, Manuel. A Era da Informação.3.ed. 2.v. São Paulo: Paz e Terra, 2002, p. 288).

20 O Estado pode permanecer autoritário em relação aos seus cidadãos sem colocar necessariamente em risco o seu desempenho econômico, desde que adquira, grosso modo, à disciplina do capital global, conseguindo desta forma ganhar competitividade com base nos custos de produção, poupanças e atracção de capitais. (FALK, Richard. Globalização predatória: uma crítica. Tradução de Rogério Alves. Lisboa: Instituto Piaget, 1999, p. 250). 
envoltos pelo fenômeno da mundialização, necessário, se faz, um novo (re)pensar do Estado, uma nova reformulação de seus aspectos e de sua caracterização.

Pensar ou repensar na estrutura do Estado é algo que deve ser buscado e alcançado para, efetivamente, se concretizar o desenvolvimento social. Aquela forma clássica não existe mais, mas sim uma nova ordem estatal está por vir, ou melhor, está a se introduzir no contexto social. Necessário buscar a sua adequação.

\section{A BUSCA DE UMA NOVA ADEQUAÇÃO DOS DIREITOS HUMANOS NO "NOVO" MODELO ESTATAL}

A passagem da era medieval para a era da modernidade ou da contemporaneidade representa uma transformação na mentalidade dos homens em âmbito mundial. A visão teocêntrica do universo cedeu lugar a uma concepção nova, o antropocentrismo ou humanismo, em que o homem ocupa o centro de todas as coisas $^{21}$.

Observa-se, no campo jurídico e filosófico, um deslocamento do centro de referência para o indivíduo detentor da dominação de tudo e centralizador de todas as coisas. Começa-se a pensar no homem como ser humano, com características universais e fundamentais.

Nesse viés, nasce a perspectiva acerca dos direitos humanos ${ }^{22}$, uma referência fundamental para o resgate da valorização da dignidade da pessoa humana como conquista fundamental e universal. Assim preceitua Bobbio (1992, p. 1) acerca dos direitos humanos:

O problema é estritamente ligado aos da democracia de da paz, aos quais dediquei a maior parte de meus escritos políticos. O reconhecimento e a proteção dos direitos humanos estão na base das Constituições democráticas modernas. A paz, por sua vez, é o

\footnotetext{
21 Essa nova concepção do universo, ou cosmovisão, conduziu a um novo teor de vida e, conseqüentemente, a novas instituições, que substituíram, por vezes violentamente, as antigas. A Idade Média findava; começava a Idade Moderna. (CICCO, Cláudio de. História do pensamento jurídico e da Filosofia do Direito. 3.ed. São Paulo: Saraiva, 2006, p. 101).

A preocupação com o tema dos direitos humanos está presente desde há muito tempo nos trabalhos jurídicos daqueles que somos preocupados com a dignidade da vida quotidiana dos indivíduos, dos grupos sociais, da humanidade e de todos os seres que habitam o planeta. (MORAIS, José Luis Bolzan de. As crises do Estado e da Constituição e a transformação espacial dos Direitos Humanos. Porto Alegre: Livraria do Advogado, 2002, p. 59).
} 
pressuposto necessário para o reconhecimento e a efetiva proteção dos direitos do homem em cada Estado e no sistema internacional. Ao mesmo tempo, o processo de democratização do sistema internacional, que é o caminho obrigatório para a busca do ideal da "paz perpétua", no sentido Kantiano da expressão, não pode avançar sem uma gradativa ampliação do reconhecimento e da proteção dos direitos do homem, acima de cada Estado.

Percebe-se, então, que a origem dos direitos humanos está calcada da historicidade dos mesmos, ou seja, os direitos acompanham as transformações sócio-histórico-político-econômicas $^{23}$, almejando alcançar real eficácia e efetividade.

As declarações de direitos foram incorporadas às Constituições de seus respectivos Estados, com o intuito de conferir-lhe maior eficácia e aplicabilidade, acarretando tal prática uma tendência mundial até a atualidade: inserir nas cartas constitucionais aqueles temas de maior importância objetivando dotar-lhes do máximo de eficácia.

Entretanto, para que se possa postular e alcançar a concretude desses direitos de âmbito fundamental e universal aos seres humanos, não é possível se fazer diante de uma sociedade tão díspar, principalmente em se tratando daqueles "países de modernidade tardia"24, como o Brasil, por exemplo. Aliás, nas palavras de Streck (2006, p. 22-23),

[...] se levarmos em conta as particularidades de um país de modernidade tardia como o Brasil, que exige - e disso estou plenamente convicto - uma teoria da Constituição adequada às suas especificidades e uma atuação interventiva da jurisdição constitucional, sem cair, à evidência, no "ativismo constitucional".

Por outro lado, não se pode pensar nos direitos humanos desatrelados à figura do Estado. Instituição que visa assegurar sua efetividade, mas que, nos dias

23 Por outro lado, essa origem histórica dos direitos humanos teve um caráter individualista, para o qual contribuiu fortemente a doutrina da Igreja. A tradição ocidental e cristã, de caráter subjetivista e individualista, estabeleceu a pedra angular da temática dos direitos humanos: a vida como sagrada, o homem como ponto culminante da criação. (CORRÊA, Darcísio. A construção da cidadania: reflexões histórico-políticas. 4.ed. Ijuí: UNUJUÍ, 2006, p. 161).

${ }_{24}$ Expressão utilizada por: STRECK, Lênio Luiz. Verdade e Consenso, Constituição, hermenêutica e teorias discursivas. Rio de Janeiro, Lúmen Júris, 2006, p. 22. 
atuais, devido à rápida insurgência da sociedade global, não está conseguindo, por si, alcançar o seu objetivo.

Inúmeras consequiências das novas formas de organização econômica e configuração de poder surgidas com a reestruturação do capitalismo e a reordenação da riqueza vêm a modificar as formas e as práticas jurídicas, afetando radicalmente a estrutura, a funcionalidade e o alcance do direito positivo. Suas normas vêm perdendo a capacidade de ordenar, moldar, conformar, controlar e regular a sociedade e a economia.

Se, por um lado, os dispositivos jurídicos avançaram significativamente nas últimas décadas, por outro, o desnível entre as classes sociais no país atinge índices alarmantes. Ricos e pobres, debaixo da mesma lei, exprimem de maneira diferenciada o rigor da justiça.

Seus mecanismos processuais também já não conseguem exercer de modo satisfatório seu papel de absorver tensões, dirimir conflitos, administrar disputas e neutralizar a violência.

Aliás, a cultura positivista da interpretação jurídica ${ }^{25}$, atualmente, tende a confundir procedimentalismo com "mero formalismo". Este "mero formalismo" implica na inefetividade real dos direitos humanos, uma vez que prescinde de decisões fundamentadas unicamente em jurisprudências e doutrinas repetitivas e sem contexto algum, escondendo a singularidade de cada caso concreto.

O procedimentalismo (teorias procedimentais da Constituição), por sua vez, é adotado como "estratégia de desjuridificação", entendida nos países centrais como "forma de favorecer o racionalismo e o pluralismo jurídico, ampliando, para seus defensores, o espaço da cidadania". ${ }^{26}$

Os direitos humanos junto com a concepção individualista da sociedade, com o passar dos anos estão adquirindo novos contornos (direitos sociais,

\footnotetext{
25 Podemos perceber que a Ciência do Direito é, em grande parte, uma Ciência Dogmática do Direito, na medida em que põe seu objeto - as normas jurídicas, quase que totalmente escritas - e parte dessas normas na sua investigação científica. Ainda que se possa caminhar de um idealismo a um empirismo, qualquer desses métodos roda em volta das normas jurídicas, que são elementos componentes do chamado sistema jurídico. Tal sistema tem por função regular os atos sociais, mas é pelas regras de interpretação - técnicas de interpretação que se chega não só a conhecer o sistema como também de aplica-lo. E ainda que se possa falar em valores aplicáveis ao Direito, os métodos não se alteram na descoberta e aplicação deles. (NUNES, Rizzatto. Manual de Filosofia do Direito. São Paulo: Saraiva, 2004, p. 317).

26 Idem, ibidem., p. 24.
} 
transindividuais, decorrentes da bioética e da informática, etc.). Com isso, além de indicadores do progresso histórico e econômico, adquirem uma complexidade que o Direito não está acostumado a lidar. Por isso, a urgência de uma mudança de perspectiva sobre os direitos humanos.

Tal emergência se deve em razão da sua não concretização no Estado Moderno. Se os direitos de segunda geração (sociais), por exemplo, ainda não foram realizados e efetivados totalmente, como se poderá chegar a uma concretização dos direitos de terceira (transindividuais), quarta (bioética, biodireito) e quinta (informática) geração, especialmente em países de modernidade tardia, em pleno desenvolvimento e repletos de problemas daí decorrentes, como é o caso brasileiro?

Dada a insurgência de vastas redes de centros decisórios no âmbito da economia globalizada, os diferentes danos morais e materiais causados pelos riscos ligados aos novos tipos de direitos dificilmente podem ser formalmente atribuídos a alguém em particular.

São danos potencialmente não-indenizáveis, o que coloca as instituições jurídicas e judiciais do Estado-Nação contemporâneo, do modo como foram concebidas e hoje se encontram estruturadas, com jurisdição territorialmente circunscrita, frente ao desafio quase intransponível de ter de se reformular radicalmente, para tentar criar alternativas institucionais, almejar oferecer respostas nacionais para questões de alcance global e conseguir neutralizar e/ou enfrentar esses problemas com um mínimo de efetividade.

Nesse sentido, pode-se concluir que, de fato, o Estado e a democracia instaurada nele é extremamente frágil: não há efetivação dos direitos garantidos constitucionalmente. O constitucionalismo está em crise e as constituições ocidentais lembram "meras folhas de papel"27, sem aplicabilidade prática, a sucumbir diante dos fatores reais de poder?

\footnotetext{
27 Segundo terminologia adotada por Ferdinand Lassale, A essência da Constituição. 6. ed. Rio de Janeiro: Lumen Juris, 2001.
} 
A história mostrou que os direitos humanos não nasceram do progresso das relações comerciais entre os povos, mas da identificação de valores comuns às diversas sociedades e grupos de uma mesma sociedade.

O Estado democrático nasceu como forma de instituição asseguradora dos direitos humanos. $\mathrm{O}$ fato social do multiculturalismo, constatado nas mais diferentes nações do planeta, impõe-se com a força das evidencias (evidências), constituindo um novo paradigma a ser integrado na ordem dos direitos cosmopolita aceitável por todos os homens. O ser humano não somente pertence, mas integra, potencialmente, uma comunidade universal.

\section{CONSIDERAÇÕES FINAIS}

Numa palavra: se o direito é um saber prático, a tarefa de qualquer teoria jurídica é buscar as condições para: a) a concretização de direitos - afinal, a Constituição (ainda) constitui - $e, b)$ ao mesmo tempo evitar decisionismos $e$ arbitrariedades interpretativas.(Lênio Luiz Streck - Verdade e Consenso)

A par do que foi verificado nos tópicos acima, é possível concluir que um dos temas mais relevantes e recorrentes no debate político e na teoria do direito refere-se ao problema da (in) efetividade dos direitos humanos.

Pode-se perceber que os direitos humanos encontram-se inseridos na situação histórica de cada cultura. Direitos humanos seriam, assim, princípios que perpassariam diferentes culturas, mas somente poderiam ser considerados como direitos na medida em que fossem incorporados pelos sistemas jurídicos nacionais.

A razão nuclear para que se considere o problema do fundamento dos direitos humanos no mesmo patamar de importância analítica da sua positividade, encontra-se, portanto, no fato de que a eficácia dos direitos humanos encontra-se ligada à sua fundamentação.

Essa fundamentação, entretanto, não irá depender de sua positivação jurídico-institucional, mas de sua legitimação em função de suas raízes éticas. $\mathrm{O}$ respeito dos direitos humanos encontra-se na análise da sua fundamentação ética e 
de como o intérprete irá lidar com a crise de modelos interpretativos pela qual o direito (especialmente o constitucional) perpassa atualmente.

Constituições dirigentes, como a brasileira, necessitam de boas respostas dos juristas-intérpretes para o problema da (in) efetividade dos direitos fundamentais. O suporte normativo para o desenvolvimento dessas respostas, na visão de Streck (2006, p. 260), está em ver a Constituição não como uma simples ferramenta, que se interpõe entre o Estado e a Sociedade, mas sim, como um documento com pretensão de eficácia, visando eliminar a falta de segurança e ordem; a desigualdade política e a pobreza (aquilo que o autor denomina de "as três violências").

Demais disso, o problema da democracia está estritamente ligado ao da (in) efetividade dos direitos fundamentais do homem, eis que quanto mais um Estado aproxima-se do ideal democrático, mais têm-se direitos para reconhecer-se aos cidadãos e, conseqüentemente, mais dificuldades se percebe para concretizá-los.

Nota-se, principalmente pela prática dos direitos sociais, que, apesar de terem sido inseridos na maioria das constituições dos "países de modernidade tardia" a partir da década de trinta, a maioria ainda não foi atingida em nenhum desses locais, o que comprova a existência de déficit de realização dos mesmos.

Diante desse quadro, muito ainda deve ser feito para que as democracias dos países em desenvolvimento como no exemplo do Brasil, concretizem e tornem seus direitos humanos efetivos, e, enfim, superem a referida condição de "folhas de papel”.

\section{REFERÊNCIAS BIBLIOGRÁFICAS}

BAUMAN, Zygmunt. Globalização: as conseqüências humana. Tradução de Marcus Penchel. Rio de Janeiro: Jorge Zahar Editor, 1999.

BEDIN, Gilmar Antonio. A sociedade internacional e o século XXI: em busca da construção de uma ordem mundial justa e solidária. Ijuí: Ed. UNIJUÍ, 2001.

BOBBIO, Norberto. A Era dos Direitos. Traduzido por Carlos Nelson Coutinho. Rio de Janeiro: Campus, 1992. Tradução de: L'età dei Diritti. 
CANOTILHO, Joaquim José Gomes. Direito Constitucional: e teoria da constituição. 6. ed. Coimbra: Almedina, 1998.

CASTELLS, Manuel. A Era da Informação. 3.ed. 2.v. São Paulo: Paz e Terra, 2002.

CICCO, Cláudio de. História do pensamento jurídico e da Filosofia do Direito. 3. ed. São Paulo: Saraiva, 2006.

CORRÊA, Darcísio. A construção da cidadania: reflexões histórico-políticas. 4.ed. Ijuí: Ed. Unijuí, 2006.

DALLARI, Dalmo de Abreu. Elementos de Teoria Geral do Estado. 25. ed. São Paulo: Saraiva, 2005.

FALK, Richard. Globalização predatória: uma crítica. Tradução de Rogério Alves. Lisboa: Instituto Piaget, 1999.

HÄBERLE, Peter. Hermenêutica Constitucional (A sociedade aberta dos intérpretes da constituição: contribuição para a interpretação pluralista $e$ "procedimental" da constituição). Traduzido por Gilmar Ferreira Mendes. Porto Alegre: Fabris, 1997.

LAFER, Celso. A reconstrução dos direitos humanos: um diálogo com o pensamento de Hannah Arendt. São Paulo: Cia. das Letras, 1988

LASSALLE, Ferdinand. A Essência da Constituição. 4. ed. Rio de Janeiro: Lumen Juris, 1998.

MALUF, Sahid. Teoria Geral do Estado. 26.ed. São Paulo: Saraiva, 2006.

MORAES, Alexandre de. Direitos Humanos Fundamentais: teoria geral, comentários aos arts. $1^{o}$ a $5^{o}$ da constituição da República Federativa do Brasil, doutrina e jurisprudência. 3. ed. São Paulo: Atlas, 2000.

MORAIS, José Luis Bolzan de. As crises do Estado e da Constituição e a transformação espacial dos direitos humanos. Porto Alegre: Livraria do Advogado, 2002.

NUNES, Rizzatto. Manual de Filosofia do Direito. São Paulo: Saraiva, 2004.

OLIVEIRA JÚNIOR, José Alcebíades de. Teoria Jurídica e novos direitos. Rio de janeiro: Lúmen Juris, 2000.

SANTOS, Antônio R. dos. Dignidade humana: trajetória e situação atual.Revista de Direito Social, Sapucaia do Sul - RS: Notadez Informações, vol. 2, p. 26-31, 2001. 
SARLET, Ingo Wolfgang. A Eficácia dos Direitos Fundamentais. Porto Alegre: Livraria do Advogado, 2001.

.Dignidade da Pessoa Humana e Direitos Fundamentais na Constituição Federal de 1988. Porto Alegre: Livraria do Advogado, 2001.

SHERRER-WARREN, Ilse. Cidadania e Multiculturalismo: a teoria social no Brasil contemporâneo. Florianópolis: Ed. UFSC, 2000,

STRECK, Lenio Luiz. Verdade e Consenso: Constituição, hermenêutica e teorias discursivas. Rio de Janeiro: Lúmen Júris, 2006.

Livraria do Advogado, 2000.

.Hermenêutica Jurídica e $(m)$ crise. 2. ed. Porto Alegre: - As crises do Estado e da Constituição e a transformação espacial dos Direitos Humanos. Porto Alegre: Livraria do Advogado, 2002.

; MORAIS, José Luis Bolzan de. Ciência Política e Teoria Geral do Estado. 3.ed. Porto Alegre: Livraria do Advogado, 2003.

WARAT, Luis Alberto. Curso seqüencial: formação de educadores desde e para os direitos humanos. Brasília: MEC, 2003, p. 12. Disponível em: <http://www.mec.gov.br/univxxi/pdf/curso1.pdf> Acesso em: 6 set. 2006. 